\title{
Proximal interphalangeal joint arthrodesis in a case of chronic proliferative osteoarthritis in the horse - a case report
}

\author{
Filip Kol’vek ${ }^{1}$, Šárka Krisová2, Kristína Žuffová ${ }^{2}, Z_{\text {deněk Žert }}^{1}$ \\ ${ }^{1}$ University of Veterinary Medicine and Pharmacy in Košice, Equine Clinic, Košice, Slovak Republic \\ ${ }^{2}$ University of Veterinary Sciences Brno, Faculty of Veterinary Medicine, Equine Clinic, Brno, Czech Republic \\ Received December 15, 2020 \\ Accepted May 26, 2021
}

\begin{abstract}
Proximal interphalangeal joint (PIPJ) arthrodesis is performed commonly in horses with chronic osteoarthritis of the pastern joint or in cases of acute traumatic injury to the pastern, in which the weight-bearing bony column must be restored. Chronic osteoarthritis of the pastern joint is a frequent cause of lameness in the equine athlete and is evidenced by chronic lameness which is supported radiographically by periosteal proliferation and loss of joint space. The conventional method of joint fusion involves the opening of the joint, debridement of the joint cartilage, osteostixis of the subchondral bone plate and application of either lag screws or plate. This case report describes the successful treatment of chronic proliferative ossified osteoarthritis and periarthritis of the proximal interphalangeal joint of the front limb of two mares by performing simple percutaneous drilling destruction of the articular cartilage and stabilization with the application of three lag screws. After three years of conservative treatment with local corticosteroids, the mares exhibited non-weight-bearing lameness. Radiographs revealed extensive periarticular new bone formation over the proximal interphalangeal joint. Three $4.5 \mathrm{~mm}$ transcortical bone screws were placed in the lag fashion. A lower limb fiberglass cast was applied in both cases for 3 days. The antibiotic and analgesic protocol included gentamicin, penicillin, and flunixin meglumine for several days. Control radiographic examination after a period of 6 and 12 months showed reduction of the periarticular bone tissue. Both of the mares in this case study successfully returned to pleasure riding after undergoing forelimb arthrodesis.
\end{abstract}

Equine, fusion, pastern joint, degenerative joint disease

"High ringbone" (chronic proliferative osteoarthritis of the proximal interphalangeal joint) in the horse is a common source of persistent lameness in older horses of any use (Stashak 2002). The exact aetiopathogenesis of the disease, which is multifactorial and includes osteochondrosis, cystic lesions, micro trauma and conformational defects, is not known (Baxter and Stashak 2011). Conservative treatment in advanced cases may be unsuccessful and repeated intraarticular application of corticosteroids can cause osteoarthropathy which does not respond to any nonsteroidal anti-inflammatory and analgesic therapy, therefore necessitating radical treatment with arthrodesis (Jones et al. 2009; Watts et al. 2010).

The process of chemical arthrodesis of the proximal interphalangeal joint (PIPJ) involving the application of alcohol or monoiodacetate (which is useful in small tarsal joints arthrodesis) (Bohanon et al. 1991; Carmalt et al. 2012) has been associated with unacceptable complications - soft tissue necrosis around the injection site, septic arthritis and necrotic tendinitis (Penraat et al. 2000). A recent clinical case analysis described a $50 \%$ success rate when applying $75 \%$ ethanol in 34 horses with high ringbone without any complications (Caston et al. 2013).

Arthrodesis in 11 horses (12 extremities) without cartilage removal, surgical opening of the joint capsule and transection of collateral ligaments of the joint were evaluated in the retrospective clinical study (Jones et al. 2009). The study documented reasonable

Address for correspondence:

Kol'vek Filip

Equine Clinic

University of Veterinary Medicine and Pharmacy in Košice

Komenského 73, 04181 Košice, Slovak Republic

Phone: +421908353274

E-mail: filip.kolvek@gmail.com

http://actavet.vfu.cz/ 
improvement in clinical difficulties of all the patients after stabilization of the osteoarthritic joint with this simplified type of arthrodesis.

A minimally invasive method using three transarticular $5.5 \mathrm{~mm}$ cortical lag screws which were introduced after the transcutaneous laser evaporation of the articular cartilage fluid was presented in six horses (Watts et al. 2010). These authors have found a method less painful than drilling because of the analgesic effect of laser energy on the neural endings within the subchondral bone, synovium and the joint capsule. They speculated that capsular contraction would provide additional joint stability caused by heating of the collagen within the joint capsule therefore not disturbing the joint congruency with cartilage removal and subchondral bone drilling.

The problem of joint cartilage destruction without disarticulation and with the sparing of the collateral ligaments was discussed in a prospective cadaveric study (Bras et al. 2011). The authors tried to avoid horizontal skin incisions, only using a longitudinal axial incision of the extensor tendon followed by 7 drilling procedures into the joint space (three medially and laterally and one axially at a $1 \mathrm{~cm}$ distance) at an angle of approximately $80^{\circ}-84^{\circ}$ to the dorsal surface of the digit. The $3.5 \mathrm{~mm} ; 4.5 \mathrm{~mm}$, and $5.5 \mathrm{~mm}$ drill bits removed $24.4 \% ; 35.5 \%$, and $45.7 \%$ of total PIPJ articular cartilage surface, respectively. The study recommended the use of a $4.5 \mathrm{~mm}$ drill bit as anything smaller was insufficient for cartilage removal and anything larger was too aggressive.

Pastern joint arthrodesis is a very useful procedure in equine surgery, offering a reduction in the pain and suffering of the patient and allowing an almost full range of movement. With this case study we would like to contribute to the discussion with our very positive experience with this minimally invasive, less expensive, but very effective method in older patients.

\section{Case description}

A 20-year-old Czech Warmblood mare and an 18-year-old Austrian Warmblood mare, both with advanced unilateral right front limb pastern joint osteoarthritis, were used for this study. Before referral and admission into the clinic, they were treated conservatively for four years by repeated local application of corticosteroids. The first three years of intraarticular treatment were successful and the mares were used for hobby riding. In the last year of the local application of steroids the joint did not respond to anti-inflammatory therapy and both mares started showing non-weight-bearing lameness and the owners insisted on a radical solution of the painful process.

The proximal interphalangeal joint had shown diffuse periarticular hard swelling; the mares were so severely lame that any flexion tests or manipulation was not advisable. Radiographic examination (Plate III, Fig. 1) revealed serious ossified periarticular reaction of joint capsule and narrowing of the joint space in the dorsopalmar view indicating crucial cartilage loss. Intraarticular diagnostic anaesthesia substantially improved the signs of lameness except for a moving deficit in the weight bearing phase of the gait. It was clear that the source of lameness was in the proximal interphalangeal joint due to aggressive osteoarthritis and periarthritis. The only speculation was whether the periarticular osseous tissue could influence the range of movement in the distal interphalangeal joint once arthrodesis was performed.

The operation was provided under general inhalation anaesthesia in lateral recumbency with the affected limb above. Destruction of the joint cartilage was done by triple application of a $5.5 \mathrm{~mm}$ drill bit through stab incisions in the skin, joint capsule, and collateral ligaments, respectively, from the lateral and medial surfaces of the joint (Plate III, Fig. 2).

Fusion of the joint was attempted without exarticulation by minimally invasive installation of the three transarticular cortical $4.5 \mathrm{~mm}$ screws through small skin and tendon stab incisions in the lag fashion in the dorsoproximal - palmarodistal direction from the 
distal part of the first phalanx to the palmar part of the second phalanx (Plate III, Fig. 2). Skin wounds were sutured and the limb was stabilized with fibreglass cast in the neutral semi-flexed position of the digit. The fibreglass cast was removed on the third day after the surgery and the mares were able to bear weight on the limb.

Antibiotic (gentamicin $6.6 \mathrm{mg} / \mathrm{kg}$ intravenously SID [ $\times 1$ a day]; penicillin $20.000 \mathrm{UI} / \mathrm{kg}$ intravenously TID [ $\times 3$ a day]) and nonsteroidal therapy was discontinued after three weeks. The limb was bandaged for six weeks. For two weeks post-operatively, the mares were permitted to move in a controlled environment only. After three months, the mares were saddled and ridden at a walk. After 5 months the owners successfully rode them at a trot. Control radiographic examination after a period of six and 12 months showed a reduction of the periarticular bone tissue, a diminishing of the soft tissue reaction, and a very advanced fusion of the joint space (Plate IV, Fig. 3). The mares can comfortably move in the paddock and have been regularly used for mild pleasure riding.

\section{Discussion}

Arthrodesis of the proximal interphalangeal joint is a radical surgical procedure minimizing the pain suffered by the horse and normalizing its movement in the case of chronic aggressive osteoarthritis and ossifying periarthritis. All cases with an acute traumatic lesion (subluxation, fracture, osteochondrosis, subchondral cyst like lesions) need to be operated using the open technique. This technique utilizes a direct approach through the digital extensor tendon and joint capsule to remove joint cartilage and to drill an opening in the subchondral bone plate (osteostixis) for enhancement of the fusion of the distal end of P1 with the proximal extremity of P2 (Lischer and Auer 2019). In the case of ossification of the joint capsule and the collateral ligaments, the separation of both joint surfaces would prove difficult and healing would be delayed or impossible because of less regenerative abilities of the inflamed and thickened ligamentous tissue (Watts et al. 2010). In this study, we decided to perform traumatic destruction of the articular cartilage conducted from the lateral and medial margins of the joint space by simple transcutaneous drilling with a $5.5 \mathrm{~mm}$ thick drill bit. Although the $5.5 \mathrm{~mm}$ drill bit led to excessive removal of cartilage and subchondral bone which may presumptively lead to implant loosening and delayed healing (Bras et al. 2011), we selected the $5.5 \mathrm{~mm}$ drill bit for these particular cases because we did not respect the drilling direction recommended by Bras et al. (2011), and we needed to destroy as much of the joint surface as possible in the simplest way. Dorsopalmar drilling was avoided and only destruction from the lateral and medial sides was performed. The choice of this type of cartilage destruction seems to be advantageous in comparison to the application of ethanol because of the serious changes in the subchondral bone plate visible on the radiograph which caused severe lameness. The same reason seems to be speaking in such advanced cases of proximal interphalangeal joint osteoarthritis against gentler laser energy joint cartilage destruction (Watts et al. 2010). Precise criteria for indication of laser surgery, chemical arthrodesis or the approach used in this study have yet to be established. This study, although containing a small sample size, hypothesizes that in cases with advanced clinical and radiological changes, this technique could be a viable option.

\section{References}

Baxter GM, Stashak TS 2011: Osteoarthritis (OA) of the PIP joint (high ringbone). In: Baxter GM (Ed): Adams and Stashak's Lameness in Horses. Sixth edn. Wiley - Blackwell Publ. Ltd., 1280 p.

Bohanon TC, Schneider RK, Weisbrode SE 1991: Fusion of the distal intertarsal and tarsometatarsal joints in the horse using intraarticular sodium monoiodoacetate. Equine Vet J 23: 289-295

Bras JJ, Lillich JD, Beard WJ, Anderson DE, Armbrust LJ, Frink E, Lease K 2011: Effect of a collateral ligament sparing surgical approach on mechanical properties of equine proximal interphalangeal joint arthrodesis constructs. Vet Surg 40: 73-81 
Carmalt JL, Bell CD, Panizzi L, Wolker RRE, Lanovaz JL, Bracamonte JL, Wilson DG 2012: Alcohol-facilitated ankylosis of the distal intertarsal and tarsometatarsal joints in horses with osteoarthritis. J Am Vet Med Assoc 240: $199-204$

Caston S, McClure S, Beug J, Kersh K, Reinertson E, Wang C 2013: Retrospective evaluation of facilitated pastern ankylosis using intra-articular ethanol injections: 34 cases (2006-2012). Equine Vet J 45: 442-447

Jones P, Delco M, Beard W, Lillich JD, Desormaux A 2009: A limited surgical approach for pastern arthrodesis in horses with severe osteoarthritis. Vet Comp Orthop Traumatol 22: 303-308

Lischer CJ, Auer JA 2019: Arthrodesis techniques. In: Auer JA, Stick J, Kümmerle JM, Prange T (Eds): Equine surgery. Fifth edn. Elsevier Inc., 1896 p.

Penraat JH, Allen AL, Fretz PB, Bailey JV 2000: An evaluation of chemical arthrodesis of the proximal interphalangeal joint in the horse by using monoiodoacetate. Can J Vet Res 64: 212-221

Stashak TS 2002: Degenerative Joint Disease of the Proximal Interphalangeal Joint. In: Stashak TS: Adams' Lameness in Horses. Fifth edn. Lippincot Williams \& Wilkins Co., 1174 p.

Watts AE, Fortier LA, Nixon AJ, Ducharme NG 2010: A technique for laser-facilitated equine pastern arthrodesis using parallel screws inserted in lag Fashion. Vet Surg 39: 244-253 
Plate III

Kol'vek F. et al.: Proximal ... pp. 155-158

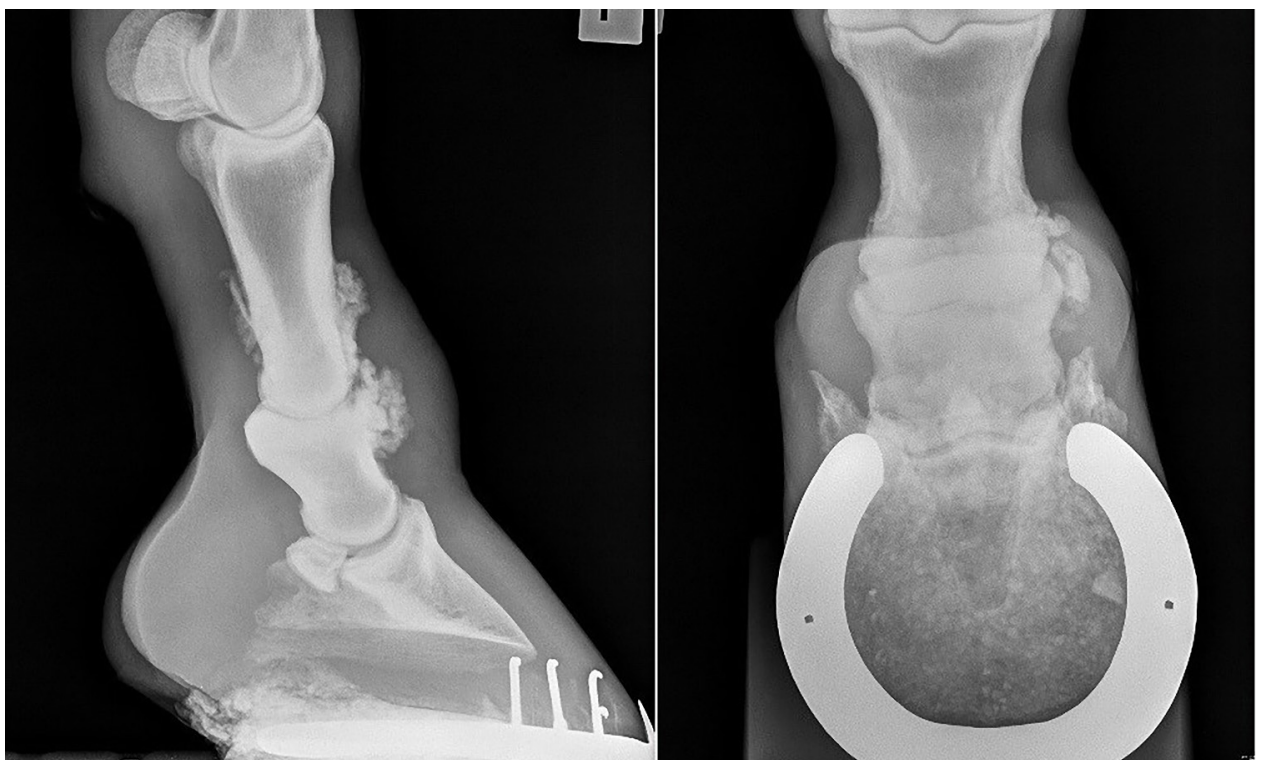

Fig. 1. X-ray examination (medial is to the left) of the pastern joint in a 20-year-old, Czech Warmblood mare, with vigorous periarticular reaction and subchondral bone lysis in the medial P2 (middle phalanx) joint surface. The mare was close to non-weightbearing lameness.

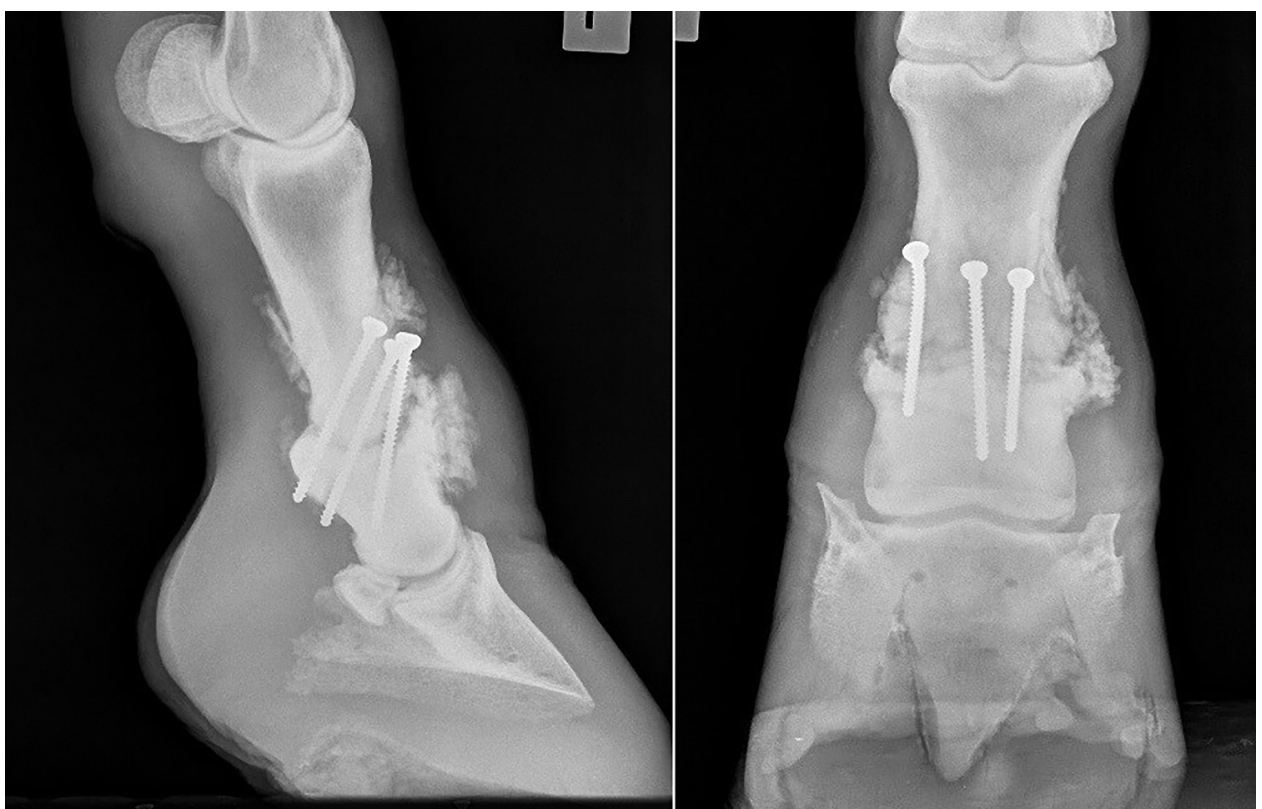

Fig. 2. Postoperative X-ray examination (medial is to the right), both views provide visibility of the increased radiolucency of the joint space due to drilling destruction of the joint cartilage and subchondral bone. That was achieved with a $5.5 \mathrm{~mm}$ drill bit from three stab incisions on the medial and lateral side. Stabilization of the joint was attained with three $4.5 \mathrm{~mm}$ cortical screws in the lag fashion. 


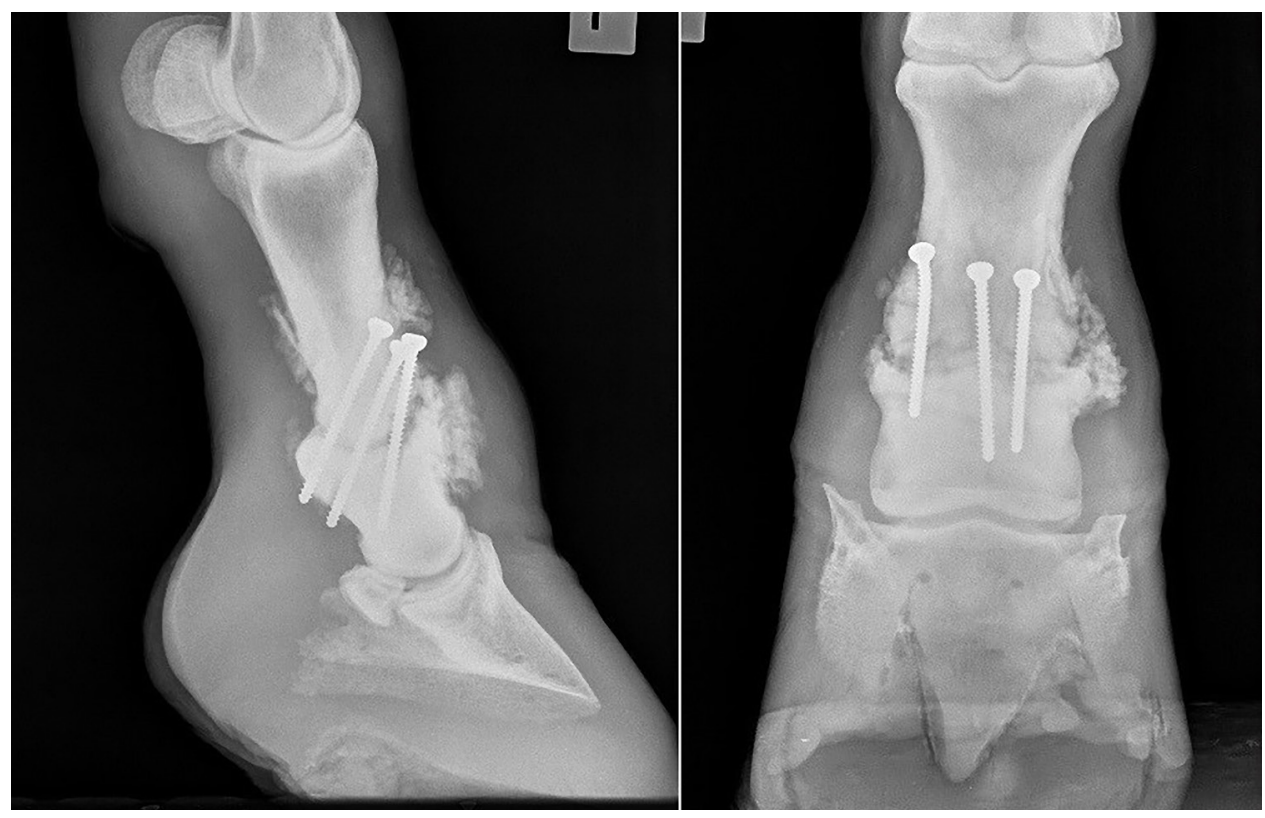

Fig. 3. X-ray examination of the proximal interphalangeal joint of the Czech Warmblood mare from Fig. 1, three months after the application of the joint implants. The mare was 2/5 lame according to the American Association of Equine Practitioners lameness grading scale, therefore the operation achieved a significant improvement of the degree of lameness. For example, the fusion of the P1 (proximal phalanx) a P2 was advanced, radiolucency of the joint space was visible, periarticular and soft tissue reaction was more visible. 